\begin{tabular}{|c|c|}
\hline Title & A Ferrite PM In-Wheel Motor Without Rare Earth Materials for Electric City Commuters \\
\hline Author(s) & Sone, Kodai; Takemoto, Masatsugu; Ogasawara, Satoshi; Takezaki, Kenichi; A kiy ama, Hidekatsu \\
\hline Citation & $\begin{array}{l}\text { IEEE Transactions on Magnetics, 48(11), 2961-2964 } \\
\text { https://doi.org/10.1109// MA G.2012.2196685 }\end{array}$ \\
\hline Issue Date & 2012-11 \\
\hline DOC URL & http:/hdl.handle.net/2115/50823 \\
\hline Rights & $\begin{array}{l}\text { ( } 2012 \text { IEEE. Reprinted, with permission, from Sone, K.; Takemoto, M.; Ogasawara, S.; Takezaki, K.; A kiy ama, H., } \\
\text { A Ferrite PM In-Wheel, Motor Without Rare Earth Materials for Electric City Commuters, IEEE Transactions on } \\
\text { Magnetics, Nov. 2012. This material is posted here with permission of the IEEE. Such permission of the IEEE does not } \\
\text { in any way imply IEEE endorsement of any of Hokkaido University products or services. Internal or personal use of this } \\
\text { material is permitted. However, permission to reprint/republish this material for advertising or promotional purposes or } \\
\text { for creating new coll lective works for resale or redistribution must be obtained from the IEEE by writing to pubs } \\
\text { permissions@ ieee.org. By choosing to view this document, you agree to all provisions of the copyright laws protecting } \\
\text { it. }\end{array}$ \\
\hline Type & article (author version) \\
\hline File Information & ToM 48-11_2961-2964.pdf \\
\hline
\end{tabular}

Instructions for use 


\title{
A Ferrite PM In-Wheel Motor without Rare Earth Materials for Electric City Commuters
}

\author{
Kodai Sone ${ }^{1}$, Masatsugu Takemoto ${ }^{1}$, Satoshi Ogasawara ${ }^{1}$, Kenichi Takezaki ${ }^{2}$, Hidekatsu Akiyama ${ }^{2}$ \\ ${ }^{1}$ Graduate School of Information Science and Technology, Hokkaido University, Sapporo, Hokkaido 060-0814 Japan \\ ${ }^{2}$ Dynax Corporation, Chitose, Hokkaido 066-8585 Japan
}

\begin{abstract}
Electric city commuters are vehicles used for commuting from suburbs to inner cities and for movement within cities. Because of the short distances that they cover and their small battery size, such vehicles are beginning to attract attention. Generally, a high-performance permanent magnet (PM) composed of rare earth elements, such as neodymium and dysprosium, is used in the inwheel PM synchronous motor (PMSM) of an electric city commuter. However, rising prices of rare earth elements and export restrictions on them are serious problems. Development of an in-wheel PMSM that does not utilize rare earth PMs is therefore highly desirable for electric city commuter vehicles. Accordingly, our research group has focused on a surface PM type axial gap structure that can achieve a high torque density and a short motor length in the axial direction. The designed motor structure with ferrite PMs replacing the rare earth PMs and the results of a three-dimensional finite element analysis are introduced in detail in this paper. Moreover, to examine the fundamental characteristics of the designed motor, a prototype is produced and tested.
\end{abstract}

Index Terms - permanent magnet synchronous motor, electric city commuter, axial gap motor, surface permanent magnet rotor structure, ferrite permanent magnet

\section{INTRODUCTION}

$\mathrm{V}$ arious efforts have been made to mitigate global warming and energy problems. In particular, electric vehicles (EVs) have attracted considerable attention and are expected to rapidly become widespread in the future. However, their inability to travel long distances with a single charge and their high battery price may prevent the spread of EVs. In contrast, electric city commuters are vehicles used for commuting from suburbs to inner city areas and for movement within cities. Such vehicles are increasingly of interest because they only need to travel short distances and have a small battery size. However, the space in an electric city commuter is limited, and thus use of an in-wheel motor is desirable. In addition to having a small size, high performance requirements such as high power output and high efficiency are generally demanded for in-wheel permanent magnet (PM) synchronous motors. Therefore, powerful rare earth PMs have been employed in such motors [1]-[2]. However, over $90 \%$ of the world's rare earth elements such as neodymium and dysprosium depend on China. Consequently, rare earth elements are expensive and have the risk of export restrictions.

This paper thus introduces a low-cost in-wheel motor for electric city commuters in which the rare earth PMs are replaced with ferrite PMs. Since the residual flux density and coercive force of a ferrite PM are small, only about $30 \%$ of those of a rare earth PM, a decrease in magnet torque is a considerable problem for ferrite PM motors. Therefore, we adopt a surface PM (SPM)-type axial gap structure, which can achieve a high torque density and short motor length in the axial direction [3]-[6]. The motor structure with a coreless rotor designed for the in-wheel motor of the electric city commuter and the results of a three-dimensional (3D) finite element analysis (FEA) are described in detail in this paper. Moreover, to examine the fundamental characteristics of the designed motor, a prototype is produced and tested. Consequently, in spite of using the ferrite PMs, by adopting the SPM-type axial gap motor with coreless rotor structure and

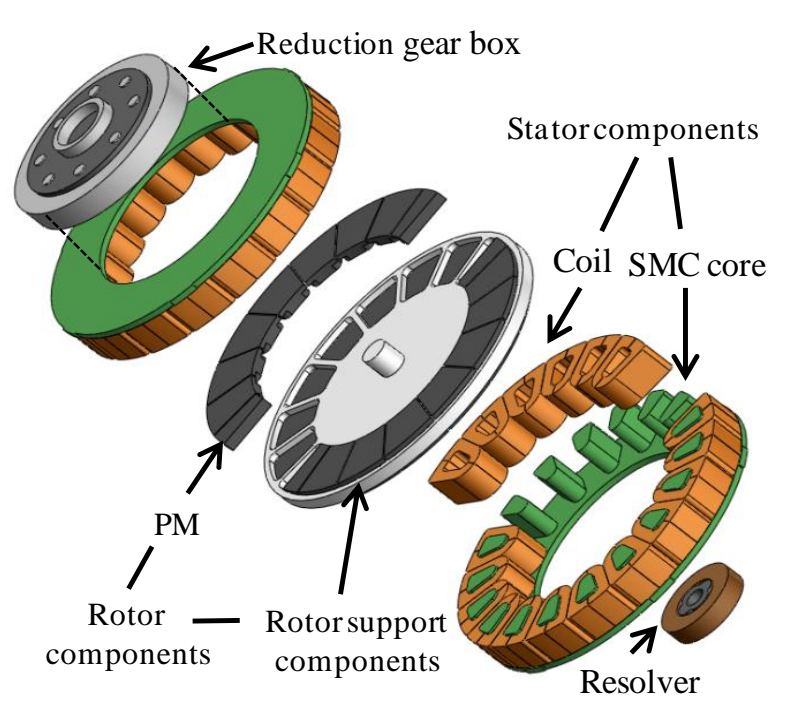

Fig. 1. Schematic of designed SPM-type axial gap motor.

incorporating a reduction gearbox inside of the stator, we show that the designed motor can satisfy the properties demanded by the in-wheel motor of an electric city commuter.

\section{Structure of Proposed SPM-Type AXIAl GAP Motor}

Fig. 1 shows a schematic of the designed motor structure. Because the motor size must be small, restricted by the wheel size of the electric city commuter, generating reluctance torque effectively is difficult. Accordingly, the magnetic torque in the designed motor is maximized through an SPM-type rotor structure constructed by inserting only ferrite PMs into a nonmagnetic stainless steel rotor support component. The designed motor therefore has a coreless rotor structure, and only magnet torque can be utilized because the motor is a nonsalient-pole machine. In addition, to meet the required torque characteristics of the electric city commuter, a reduction gearbox with a gear ratio of 5:1 is inserted into one end of the stator (Fig. 1). Conversely, a resolver is inserted into the other 
TABLE I

SPECIFICATIONS OF DESIGNED MOTOR

\begin{tabular}{cc}
\hline Outer diameter of motor & $200 \mathrm{~mm}$ \\
Outer diameter of rotor & $202 \mathrm{~mm}$ \\
Total motor axial length & $71.7 \mathrm{~mm}$ \\
PM thickness & $14.3 \mathrm{~mm}$ \\
Arc angle of PM & $22.5^{\circ}$ \\
Number of poles & 16 \\
Number of slots & 18 \\
Slot fill factor of coil & $48.7 \%$ \\
Air gap & $1.2 \mathrm{~mm}$ \\
\hline
\end{tabular}

TABLE II

TARGET VALUE AND ANALYSIS RESULTS OF DESIGNED MOTOR

\begin{tabular}{ccc}
\hline \hline & Target value & Analysis results \\
Maximum torque & $30 \mathrm{Nm}$ & $32.36 \mathrm{Nm}$ \\
Volume & $1.43 \mathrm{~L}$ & $1.43 \mathrm{~L}$ \\
Maximum power & $5 \mathrm{~kW}$ & $5.41 \mathrm{~kW}$ \\
Maximum torque density & $20.97 \mathrm{Nm} / \mathrm{L}$ & $22.59 \mathrm{Nm} / \mathrm{L}$ \\
Rated speed & 1600 & 1600 \\
Maximum speed & 5000 & 5000 \\
\hline
\end{tabular}

end of the stator. The designed motor thus utilizes the limited wheel space effectively. The motor's form and the number of poles and slots are determined such that the magnet torque is maximized for the restricted motor size. Tables I and II list the specifications of the designed motor and the target values demanded by the electric city commuter, respectively. The dimensions of each part of the designed motor are thus optimized by repeatedly performing 3D FEA until the target values in Table II are satisfied. The air gap is wide at $1.2 \mathrm{~mm}$ in consideration of the assembly. The analysis results also listed in Table II are discussed in Section III. This designed motor can realize a wide range of speeds at constant power output by field weakening control in spite of the SPM structure.

Rare earth PMs have conventionally been used as key components in realizing in-wheel motors for EVs [1]-[2]. However, by replacing rare earth PMs with ferrite PMs, the designed motor can achieve sufficient performance by adopting a coreless rotor structure and installing the reduction gearbox inside the stator. The coreless rotor structure without a back yoke of magnetic steel is also effective in suppressing the irreversible demagnetization that becomes a problem in ferrite PMs. Moreover, the coreless rotor structure is expected to have high efficiency, owing to its suppression of iron loss, because this rotor structure can lower the magnetic flux density in the motor.

\section{RESULTS OF 3D FEA}

3D FEA for the designed motor is performed with JMAGStudio simulation software. Analysis results of the torque characteristics and resistance to irreversible demagnetization of the PMs are discussed here. Furthermore, we investigate the durability of our motor to the stress caused by rotating the rotor through results obtained with SolidWorks 3D CAD software.

\section{A. Torque Characteristics}

Fig. 2 shows the change in instantaneous and cogging torques with rotational angle found through 3D FEA. Table II then lists the analysis results of the designed motor derived from Fig. 2. The temperature of the ferrite PMs is constant at $75^{\circ} \mathrm{C}$. The maximum average torque of the designed motor is 32.36 Nm, which satisfies the target value at the maximum

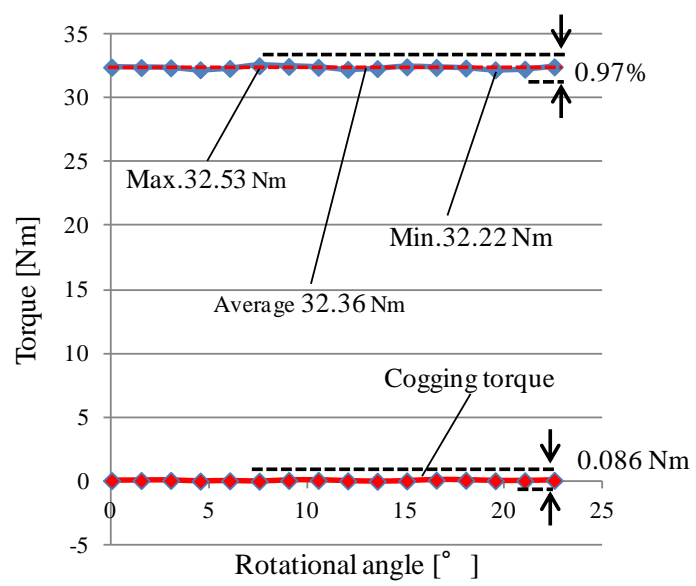

Fig. 2. Changes in instantaneous and cogging torques with rotational angle at a maximum current density of $11.2 \mathrm{Arms} / \mathrm{mm}^{2}$. Peak-to-peak torque ripple is $0.97 \%$.

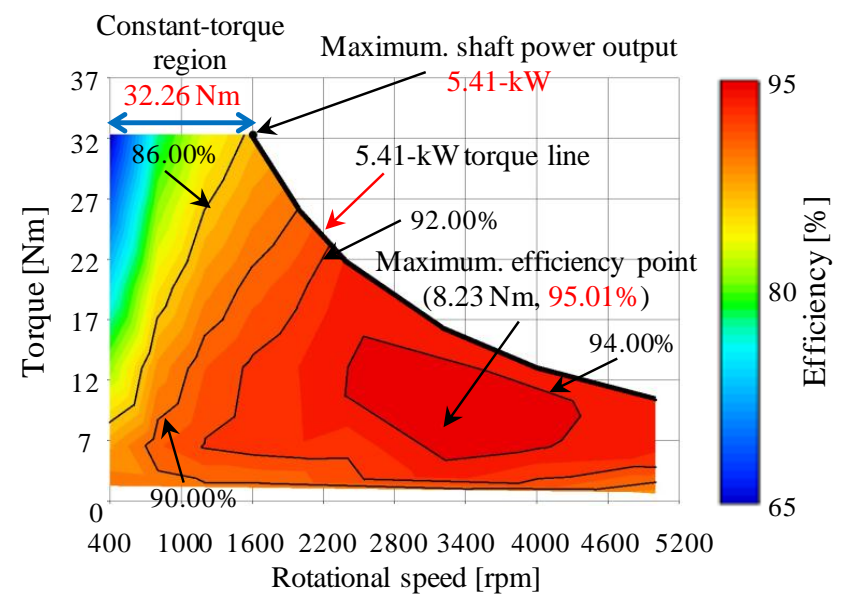

Fig. 3. Efficiency map of constant torque and power output operations for designed motor. The solid line denotes torques realizing a constant output of $5.41 \mathrm{~kW}$.

current density of $11.2 \mathrm{Arms} / \mathrm{mm}^{2}$. The peak-to-peak torque ripple is sufficiently small at $0.97 \%$. Additionally, the peak-topeak cogging torque is very small at $0.086 \mathrm{Nm}$, and is only $0.27 \%$ of the maximum average torque of $32.36 \mathrm{Nm}$.

\section{B. Constant Power Output Operation and Efficiency Map}

Fig. 3 shows the efficiency map of constant torque and power output operations for the designed motor. The solid line denotes torques realizing a constant power output of $5.41 \mathrm{~kW}$ at rotational speeds from 1600 to $5000 \mathrm{r} / \mathrm{min}$. When performing the analysis, the DC voltage of the inverter is constant at the battery voltage of $200 \mathrm{~V}$. The results establish that the designed motor can achieve a constant power output operation greater than the target value of $5.0 \mathrm{~kW}$ by means of field weakening control.

The motor efficiency is calculated from the torque, iron loss, and copper loss determined by 3D FEA. The iron loss is derived from the sum of hysteresis loss and eddy-current loss in the stator core and the eddy-current loss in the rotor support component. Since the iron loss in the ferrite PMs is negligible in comparison, this loss is ignored in the analysis. Fig. 3 was generated by extracting the results attaining the highest efficiency at each current and rotational speed from numerous 


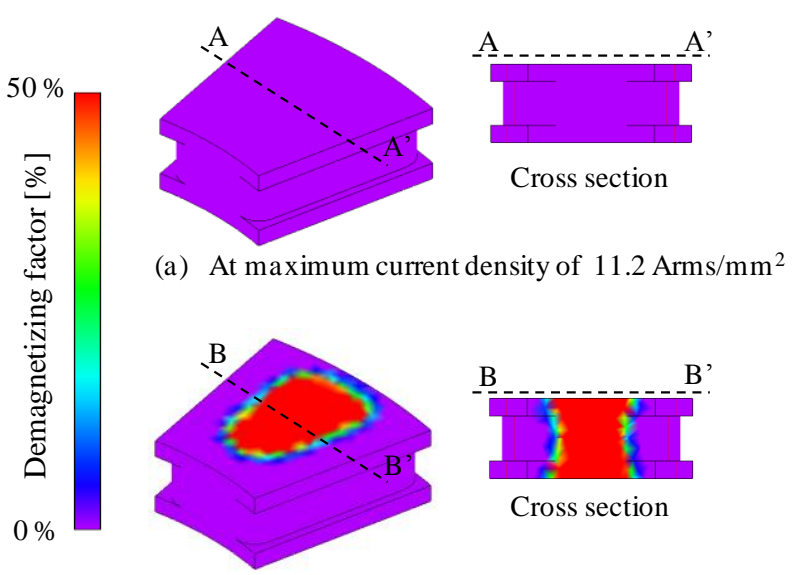

(b) At 3-fold maximum current density

Fig. 4. FEA results of irreversible demagnetization of ferrite PM at the maximum current density of $11.2 \mathrm{Arms} / \mathrm{mm}^{2}$ and 3-fold the maximum current density.

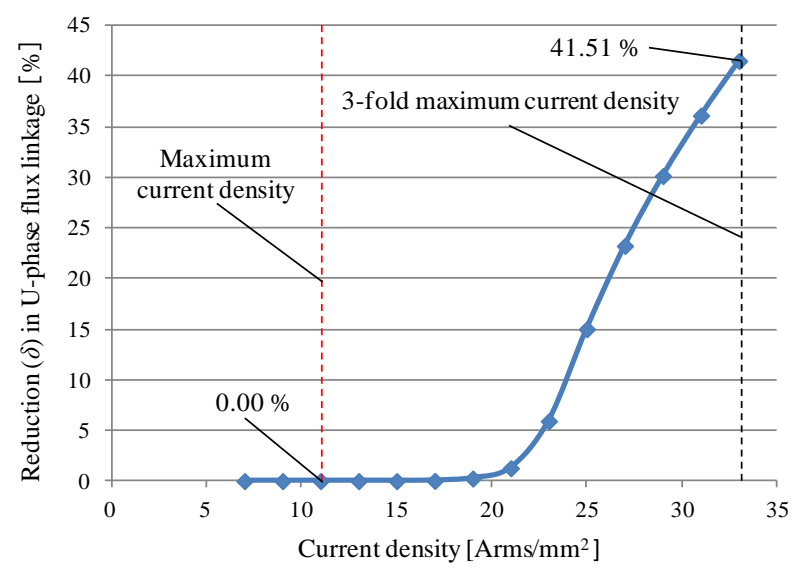

Fig. 5. Relation between current density and reduction $(\delta)$ in U-phase flux linkage.

calculations by precisely adjusting the magnitude and phase angle of the current in the 3D FEA. As shown in the figure, the efficiency is high for a wide range of high speeds, and the maximum efficiency is $95.01 \%$ at $3200 \mathrm{r} / \mathrm{min}$.

\section{Durability to Irreversible Demagnetization of PMs}

Verifying that the field weakening operation does not cause irreversible demagnetization of the ferrite PMs in the designed motor is imperative. To this end, we perform 3D FEA to investigate the irreversible demagnetization of the ferrite PMs under the conditions that the current phase angle is constant at $90^{\circ}$ and the temperature of the ferrite PMs is $-40^{\circ} \mathrm{C}$. The field weakening flux at the current phase angle of $90^{\circ}$ is directly opposed to the magnetizing direction of the ferrite PMs. In addition, irreversible demagnetization tends to occur in ferrite PMs when the magnet temperature becomes low. Our analysis condition on the temperature is thus the worst-case scenario for the ferrite PMs. Fig. 4 shows 3D FEA results for a ferrite PM in the designed motor displaying the highest irreversible demagnetization factor. At the maximum current density of 11.2 Arms $/ \mathrm{mm}^{2}$, irreversible demagnetization of the ferrite PM clearly does not occur. In contrast, as an extreme example, irreversible demagnetization occurs extensively in the ferrite $\mathrm{PM}$ at 3-fold the maximum current density.

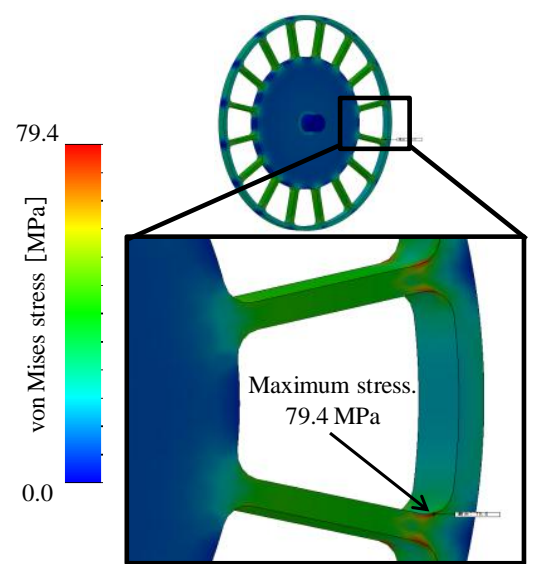

Fig. 6. 3D stress analysis of the rotor at maximum rotation speed of 5000 $\mathrm{r} / \mathrm{min}$.

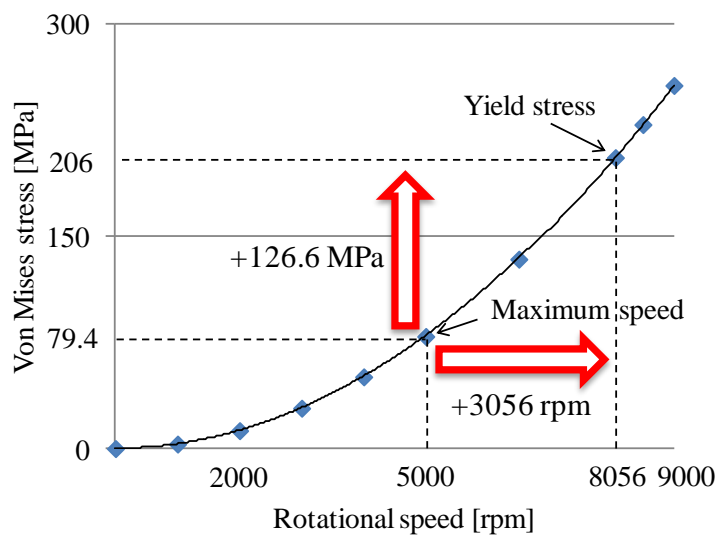

Fig. 7. Relation between von Mises stress and rotational speed.

Fig. 5 shows the reduction $(\delta)$ in the U-phase flux linkage generated by the ferrite PMs. $\delta$ is an index that represents the state of a PM's irreversible demagnetization and is defined as

$$
\delta=\frac{\psi_{m b}-\psi_{m a}}{\psi_{m b}} \times 100[\%] .
$$

Here, $\Psi_{m b}$ and $\Psi_{m a}$ are the U-phase flux linkages generated by the ferrite PMs before and after conduction of current, respectively. At the maximum current density, $\delta=0.00 \%$. However, $\delta$ increases rapidly when the current density exceeds $21 \mathrm{Arms} / \mathrm{mm}^{2}$; that is, 1.88 -fold the maximum current density. The designed motor can thus resist irreversible demagnetization at the maximum current density.

\section{Durability to Stress Caused by Rotating Rotor}

Rotor stress is known to increase in proportion to the square of the rotational speed. Therefore, a stress analysis is also performed on the designed motor. Since the maximum rotational speed of the designed motor is $5000 \mathrm{r} / \mathrm{min}$, the analysis is conducted using this speed. Fig. 6 shows the analysis results. A maximum von Mises stress of $79.4 \mathrm{MPa}$ is found at the location indicated by the arrow. The $18 \mathrm{Cr}-8 \mathrm{Ni}$ austenitic steel used for the rotor support component has the lowest yield strength at $206 \mathrm{MPa}$. Fig. 7 shows the relation between maximum von Mises stress and rotational speed. When the rotational speed is $8056 \mathrm{r} / \mathrm{min}$, the maximum von Mises stress reaches $206 \mathrm{MPa}$, the minimum yield strength of the component. The safety factor for the rotational speed is 


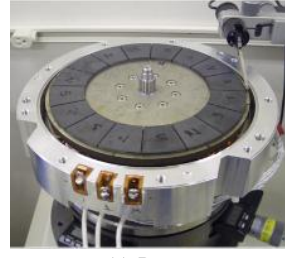

(a) Rotor

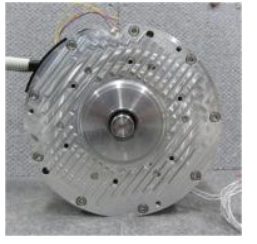

(c) Front view

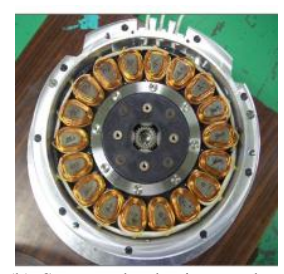

(b) Stator and reduction gearbox

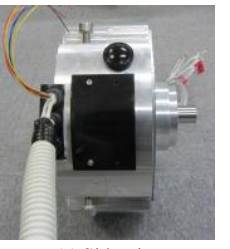

(c) Side view
Fig. 8. Photographs of designed motor prototype.

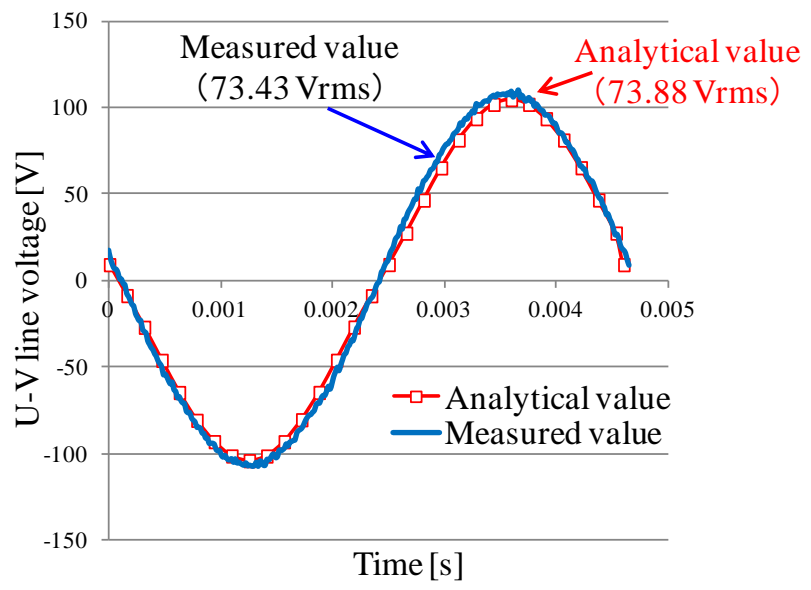

Fig. 9. U-V line voltage of prototype at base speed $1600 \mathrm{r} / \mathrm{min}$

therefore considered sufficiently high at 1.61 .

\section{PROTOTYPE CONFIGURATION}

Fig. 8(a) shows a photograph of the rotor in a prototype of the designed motor. The ferrite PMs are fixed into the rotor support component with an adhesive. Fig. 8(b) shows the reduction gearbox and stator in the prototype. The limited wheel space is used effectively by the axial gap structure, because the reduction gearbox is inserted into the stator. The stator core is constructed by fixing a soft magnetic composite (SMC) core to the case with screws and adhesive. Figs. 8(c) and (d) then show the exterior of the prototype.

\section{EXPERIMENT RESULTS}

\section{A. Unloaded Test}

Fig. 9 shows the U-V line voltage waveform (i.e., the waveform of the induced electromotive force) when the prototype is not loaded. The rotational speed here is the base speed of $1600 \mathrm{r} / \mathrm{min}$ (Table II). The measured and analysis values of U-V line voltage are 73.43 and 73.88 Vrms, respectively. Thus, the values are in good agreement, and the prototype of the designed motor can be analyzed accurately through 3D FEA. Moreover, the induced electromotive force of the prototype has an almost perfect sinusoidal waveform. In fact, the total harmonic distortion is small at $1.60 \%$, and therefore the designed motor is considered to have excellent

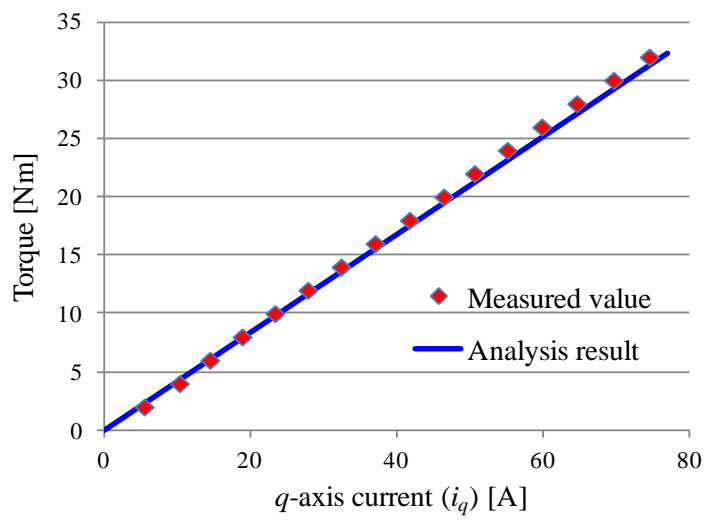

Fig. 10. Relationship between torque and $q$-axis current $i_{q}$ under loading test. The maximum torque is $30.0 \mathrm{Nm}$.

current control. Furthermore, the cogging torque of this prototype can be assumed to be small (as shown in Fig. 2) because of the small total harmonic distortion of the induced electromotive force.

\section{B. Loading Test}

Fig. 10 shows the relation between torque and $q$-axis current $\left(i_{q}\right)$ when the motor is subjected to loading, where the solid blue line denotes the result determined through 3D FEA of the designed motor. The analysis and measured results are almost equal. We can thus verify that the measured torque of the prototype exceeds the target value of $30.0 \mathrm{Nm}$ at the current density of $10.12 \mathrm{Arms} / \mathrm{mm}^{2}$.

\section{CONCLUSION}

In this paper, we examined an in-wheel type axial gap motor using ferrite PMs for an electric city commuter and reported 3D FEA results for this motor. To examine the fundamental characteristics of the designed motor, we also produced and tested a prototype model. As a result, we found that the designed motor satisfies the target values of the electric city commuter. Future work includes continuing with loading tests such that the constant power output operation and efficiency map of the prototype can be verified.

\section{REFERENCES}

[1] Y.-P. Yang and D. S. Chuang, "Optimal design and control of a wheel motor for electric passenger cars," IEEE Trans. Magn., vol. 43, no. 1,pp. 51-61, Jan. 2007.

[2] C. Versele, Z. De Greve, F. Vallee, R. Hanuise, O. Deblecker, M. Delhaye, and J. Lobry, "Analytical design of an axial flux permanent magnet in-wheel synchronous motor for electric vehicle", in Proc. of 13th European Conference on Power Electronics and Applications (EPE '09), 9 pages (CD-ROM), Sept. 2009.

[3] M. Aydin, S. Huang, and T. A. Lipo "Torque Quality and Comparison of Internal and External Rotor Axial Flux Surface-Magnet Disc Machines", IEEE Trans. Ind. Electronics, Vol. 53, No. 3, pp. 822-830, June 2006.

[4] M. Aydin, S. Huang, and T.A. Lipo, "Axial Flux Permanent Magnet DiscMachines: A Review", in Conf. Record of SPEEDAM, pp. 61-71, May 2004.

[5] T. J. Woolmer and M. D. McCulloch, "Analysis of the Yokeless And Segmented Armature Machine", in Proc. 2007 IEEE Int. Electric Machines and Drives Conf. (IEMDC '07), pp.704-708, 2007.

[6] W. Fei, P. Luk, and K. Jinupun, "A new axial flux permanent magnet Segmented-Armature-Torus machine for in-wheel direct drive applications", in Proc. of 2008 IEEE Power Electronics Specialists Conf. (PESC 2008), pp.2197-2202, 2008. 